\title{
Bone-Targeted Nanoplatform Combining Zoledronate and Photothermal Therapy To Treat Breast Cancer Bone Metastasis
}

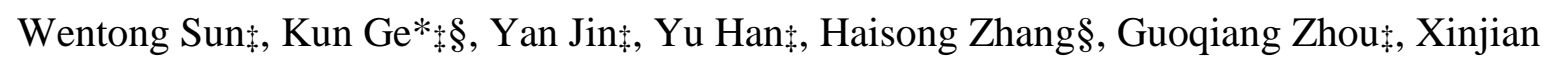

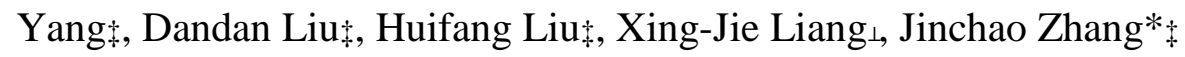

$\ddagger$ Key Laboratory of Chemical Biology of Hebei Province, Key Laboratory of Medicinal Chemistry and Molecular Diagnosis of the Ministry of Education, College of Chemistry and Environmental Science, Hebei University, Baoding 071002, P.R. China

$\S$ Hebei Key Laboratory of Chronic Kidney Diseases and Bone Metabolism, Affiliated Hospital of Hebei University, Baoding 071000, P.R. China

${ }_{\perp}$ CAS Key Laboratory for Biomedical Effects of Nanomaterials and Nanosafety, CAS Center for Excellence in Nanoscience, National Center for Nanoscience and Technology of China, No. 11, First North Road, Zhongguancun, Beijing, 100190, P.R. China

Corresponding Authors

* K. Ge. E-mail: kaqikun@163.com.

* J. Zhang. E-mail: jczhang6970@163.com. 


\section{Methods}

Preparation of gold nanorods. Gold nanorods were synthesized by reported method with some modifications. ${ }^{1}$ First, the same volumes of CTAB $(200 \mathrm{mM})$ and $\mathrm{HAuCl}(0.5 \mathrm{mM})$ were mixed together (total $2 \mathrm{~mL}$ ), and $0.12 \mathrm{~mL}$ of ice-cold $10 \mathrm{mM} \mathrm{NaBH}_{4}$ was thrown into the above mixture to aquire a seed solution, which was further vigorously stirred for 2 min and held at $25{ }^{\circ} \mathrm{C}$. Second, $1.3 \mathrm{~mL}$ of $80 \mathrm{mM}$ ascorbic acid was slowly dropped to a mix solution (50 mL of $200 \mathrm{mM} \mathrm{CTAB}, 2.8 \mathrm{~mL}$ of $4 \mathrm{mM} \mathrm{AgNO}_{3}, 3.25 \mathrm{~mL}$ of $23 \mathrm{mM} \mathrm{HAuCl}_{4}$ and $48 \mathrm{~mL}$ ultrapure water were mixed together) until it became colorless to obtain the growth solution, which should be held at $27-30{ }^{\circ} \mathrm{C}$ during the whole procedure. Third, $0.9 \mathrm{~mL}$ of the seed solution was added into the growth solution to aquire the gold nanorods.

Preparation of Au@MSNs. For preparation of Au@MSNs, a procedure was used with some modifications. ${ }^{1,2}$ The as-synthesized gold nanorods were centrifuged to remove excess surfactant $\mathrm{CTAB}$, and then the gold nanorods were dispersed in $50 \mathrm{~mL}$ of ultrapure water and added with $500 \mu \mathrm{L}$ of $100 \mathrm{mM} \mathrm{NaOH}$ under vigorously stirring. After that, $150 \mu \mathrm{L}$ of $20 \%$ TEOS in methanol was dropped to above suspension with gentle stir, and after a 30-60 mins interval, repeated the same dropping for two times. The mixture kept to react for $6 \mathrm{~h}$. To remove $\mathrm{CTAB}$, the red precipitate was refluxed for $1 \mathrm{~h}$ in a mixed solution of $0.2 \mathrm{~mL}$ of $\mathrm{HCl}$ and $20 \mathrm{~mL}$ of methanol and followed by extensively washing with hot methanol. FITC-labeled Au@MSNs (Au@MSNs-FITC) were prepared by adding FITC-APTES and TEOS by a co-condensation route. ${ }^{3}$

Preparation of Au@MSNs-NH2. The amine group was functionalized in Au@MSNs by APTES according to reported work. ${ }^{3}$ Briefly, 50 mg of Au@MSNs were dispersed into 40 
$\mathrm{mL}$ of ethanol and refluxed for $24 \mathrm{~h}$, and then added $100 \mu \mathrm{L}$ APTES. After washed for several times, the obtained Au@MSNs- $\mathrm{NH}_{2}$ were dispersed in DMSO.

Preparation of Au@MSNs-ZOL. Firstly ZOL was activated by CDI according to previous work. ${ }^{4}$ Then $50 \mathrm{mg}$ of Au@MSNs-NH $\mathrm{NH}_{2}$ and $22.6 \mathrm{mg}$ activated ZOL were dispersed in $10 \mathrm{~mL}$ of DMSO in a vessel which contained $2 \mathrm{~mL}$ triethylamine under nitrogen protection for 12 h. FITC-labeled Au@MSNs-ZOL (Au@MSNs-ZOL-FITC) were prepared as Au@MSNs-FITC.

Characterizations. Transmission electron microscopy images were obtained by a Tecnai G2 F20 S-TWIN transmission electron microscope (FEI). The $\mathrm{N}_{2}$ adsorption/desorption isotherms, BET surface area, and pore volume were determined by a Micromeritics ASAP $2010 \mathrm{M}$ instrument. UV-Vis absorption spectra were obtained using a UV-3600 instrument (Shimadzu). FTIR spectra were recorded by a Nicolet iS10 instrument (ThermoFisher). Thermogravimetry analysis was recorded by a STA449C thermal analysis instrument (Netzsch). Zeta potential was obtained by a Nano-ZS system (Malvern Instruments). Photothermal responses of Au@MSNs-ZOL and pure water were recorded by an infrared thermal camera (Testo 870-2) after irradiation with an $808 \mathrm{~nm}$ laser (BWT Beijing Ltd).

Experimental animals. All the ICR and NUNU/nude mice were provided from Beijing Vital River Laboratory Animal Technology Co., Ltd and the mouse experiments were carried out at Medical Comprehensive Experimental Center of Hebei University according to the rules of the Animal Welfare and Ethical Committee of Hebei University.

Cell culture. Human breast cancer cell line MDA-MB231 and mouse osteoblast cell line MC3T3-E1 were cultured with high-suger DMEM and $\alpha$-MEM respectively, containing 10\% 
FBS, $100 \mathrm{U} / \mathrm{mL}$ penicillin and $100 \mathrm{U} / \mathrm{mL}$ streptomycin, $37{ }^{\circ} \mathrm{C}$ in a humidified $5 \% \mathrm{CO}_{2}$ atmosphere.

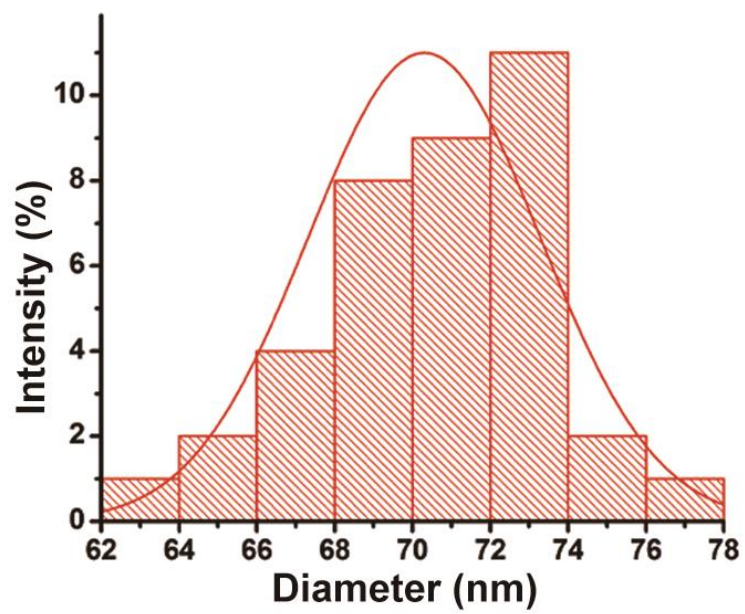

Fig. S1 Size distribution of Au@MSNs measured from TEM images.

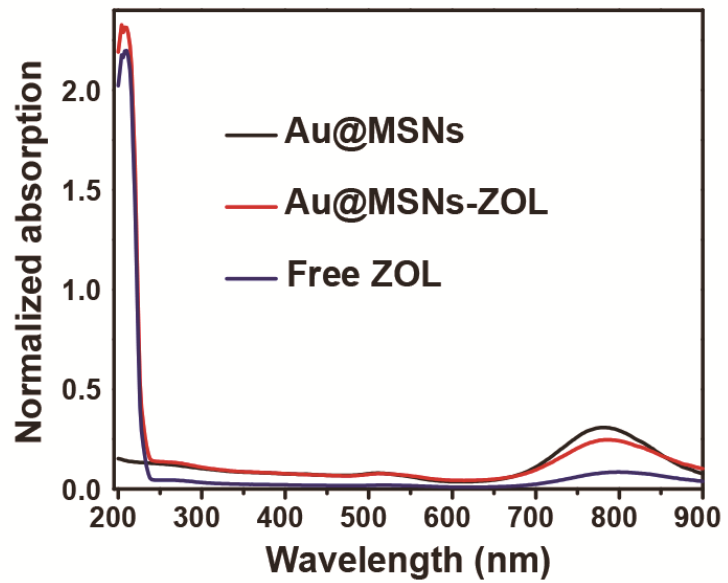

Fig. S2 UV-vis spectroscopy spectra of the Au@MSNs, free ZOL, and Au@MSNs-ZOL. 


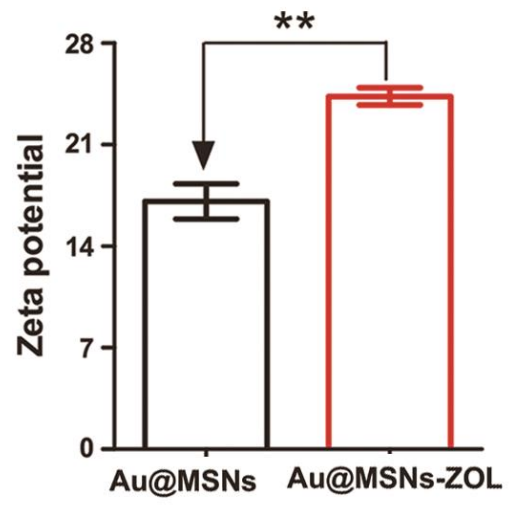

Fig.S3 Zeta potential of Au@MSNs and Au@MSNs-ZOL.

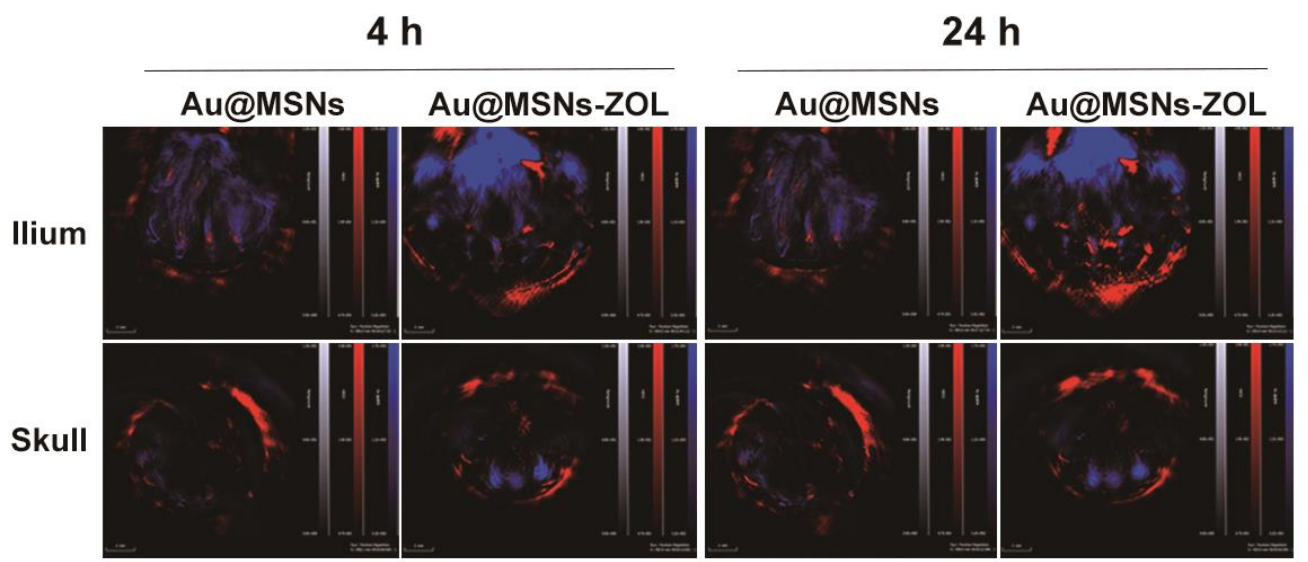

Fig. S4 The overlaid PA signals of the hemoglobin (red) and gold rod (blue) after intravenous injection with Au@MSNs and Au@MSNs-ZOL for 4 and 24 h. 

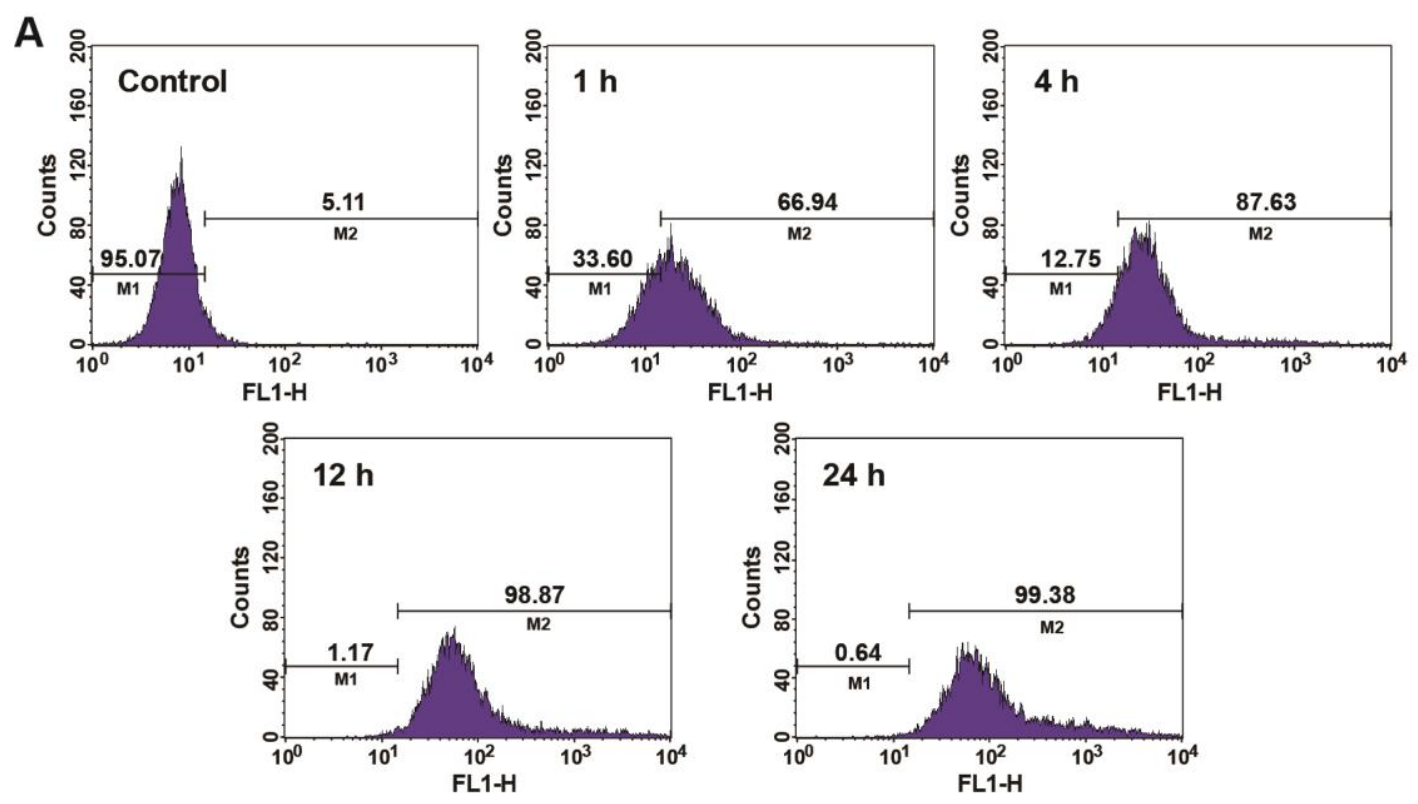

B $1 \mathrm{~h}$

$4 \mathrm{~h}$

$12 \mathrm{~h}$

$24 \mathrm{~h}$
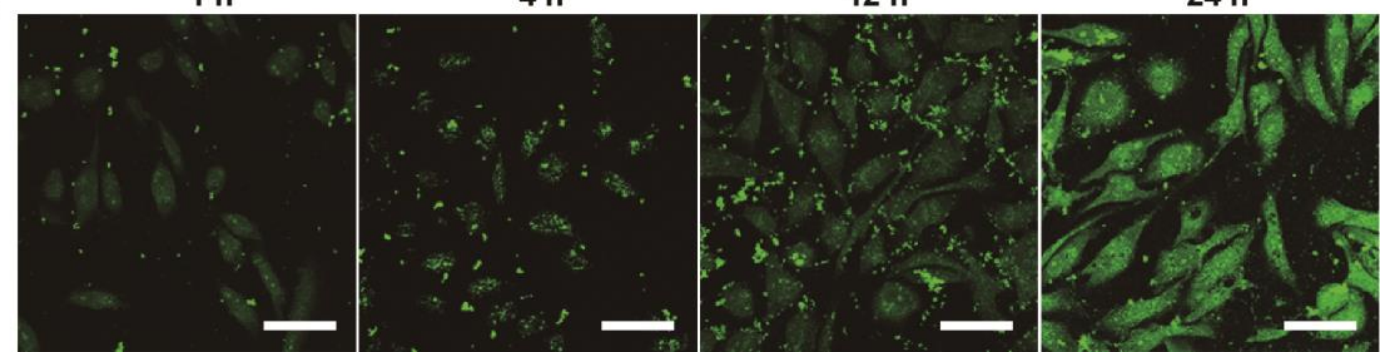

Fig. S5 Au@MSNs-ZOL-FITC uptake in MDA-MB-231 cells for 1, 4, 12 and $24 \mathrm{~h}$ at $37^{\circ} \mathrm{C}$.

Intracellular fluorencence signal (A) and fluorescence images of FITC (B) in MDA-MB-231 cells after treated with Au@MSNs-ZOL-FITC for 1, 4, 12, and $24 \mathrm{~h}$ at $37{ }^{\circ} \mathrm{C}$. Scale bar is 40 $\mu \mathrm{m}$. 

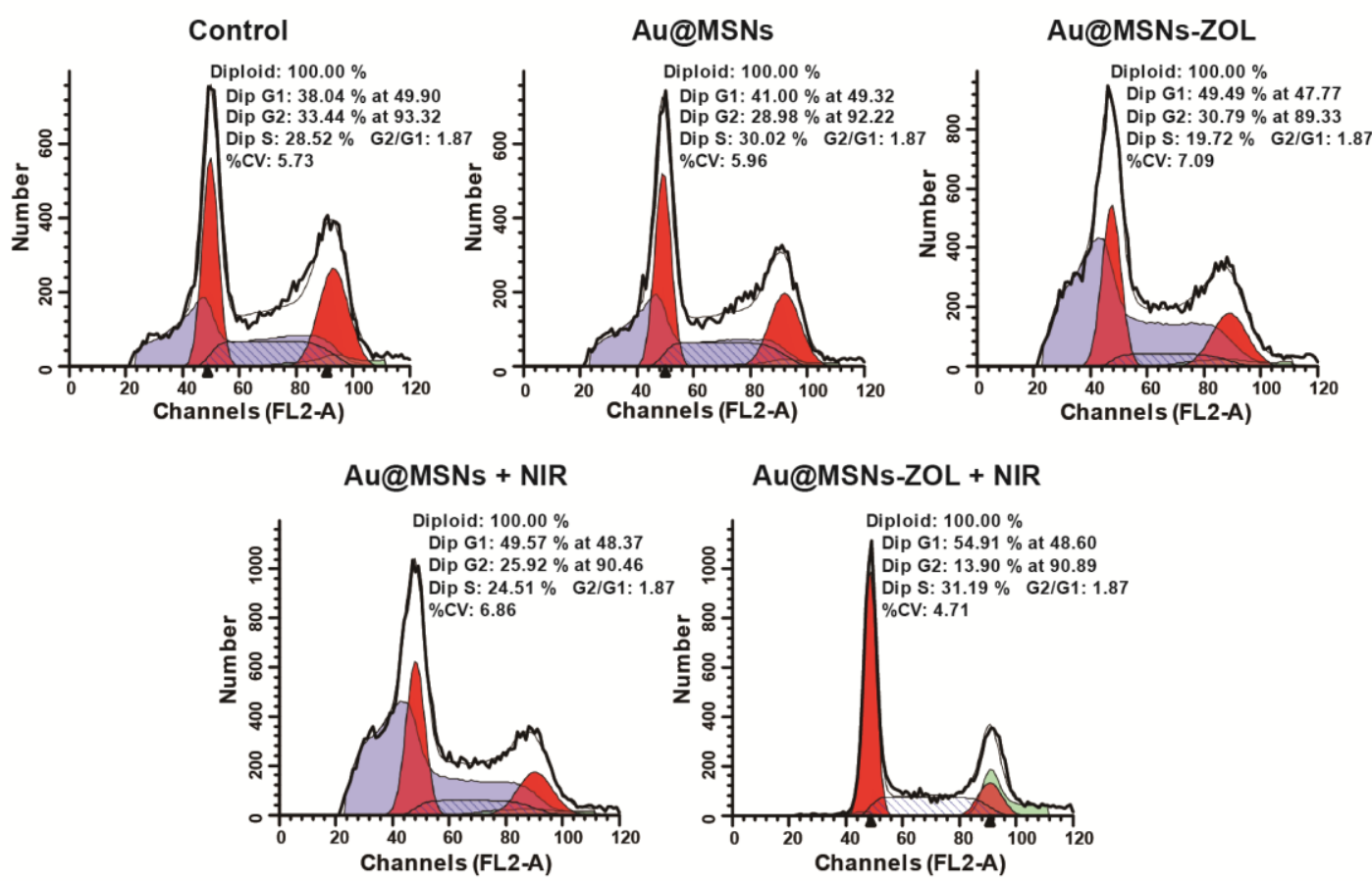

Au@MSNs-ZOL + NIR
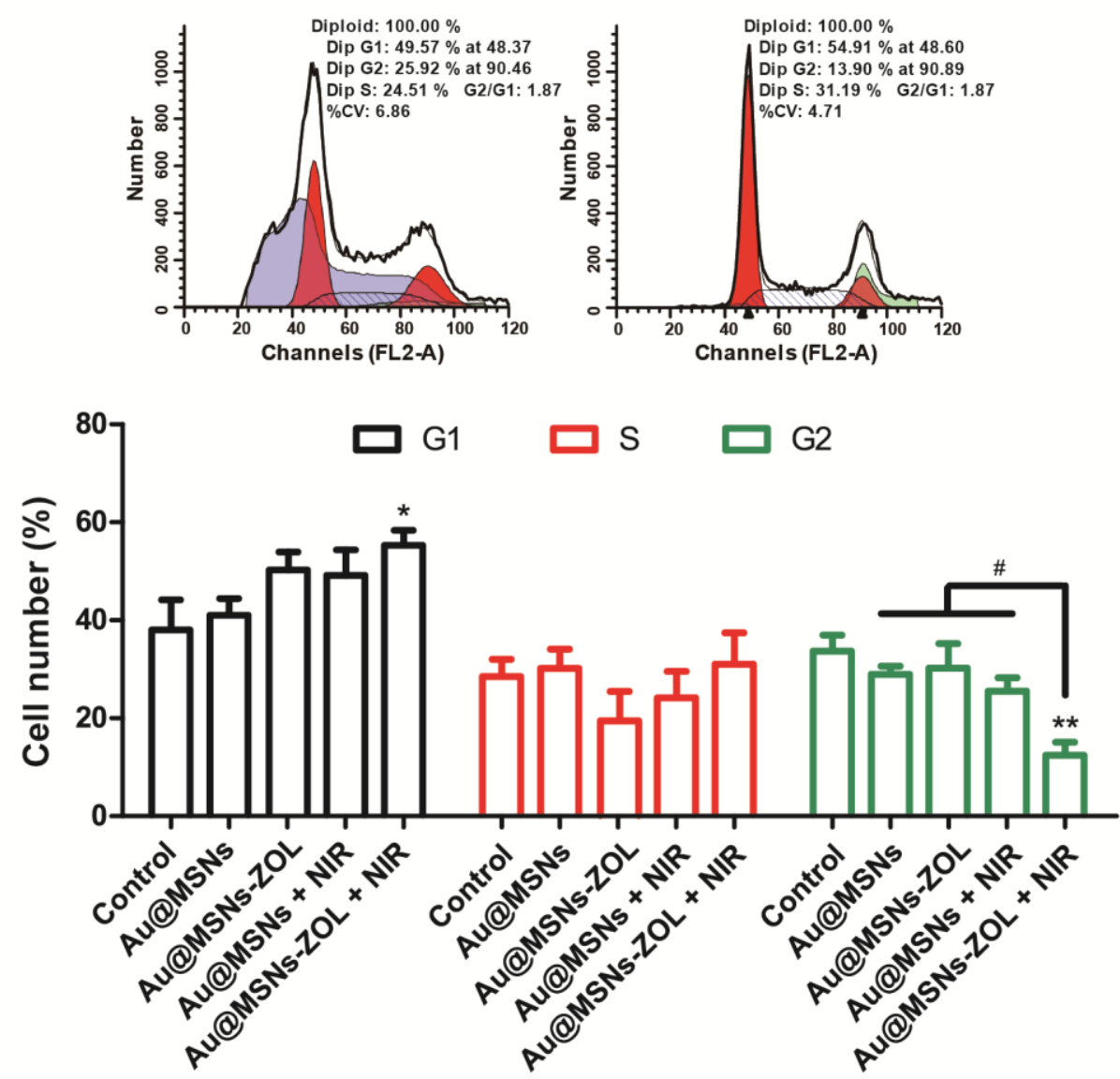

Fig. S6 Cell cycle of MDA-MB231 treated with PBS, Au@MSNs, Au@MSNs-ZOL, combination of Au@MSNs and NIR, and combination of Au@MSNs-ZOL and NIR for 24 h. *P<0.05, $\quad * * \mathrm{P}<0.01 \quad$ for $\quad \mathrm{Au} @ \mathrm{MSNs}, \quad \mathrm{Au} @ \mathrm{MSNs}-\mathrm{ZOL}, \quad \mathrm{Au} @ \mathrm{MSNs}+\mathrm{NIR}, \quad$ and Au@MSNs-ZOL+NIR vs control group; \#P<0.05 for Au@MSNs-ZOL+NIR vs Au@MSNs, Au@MSNs-ZOL and Au@MSNs+NIR. 


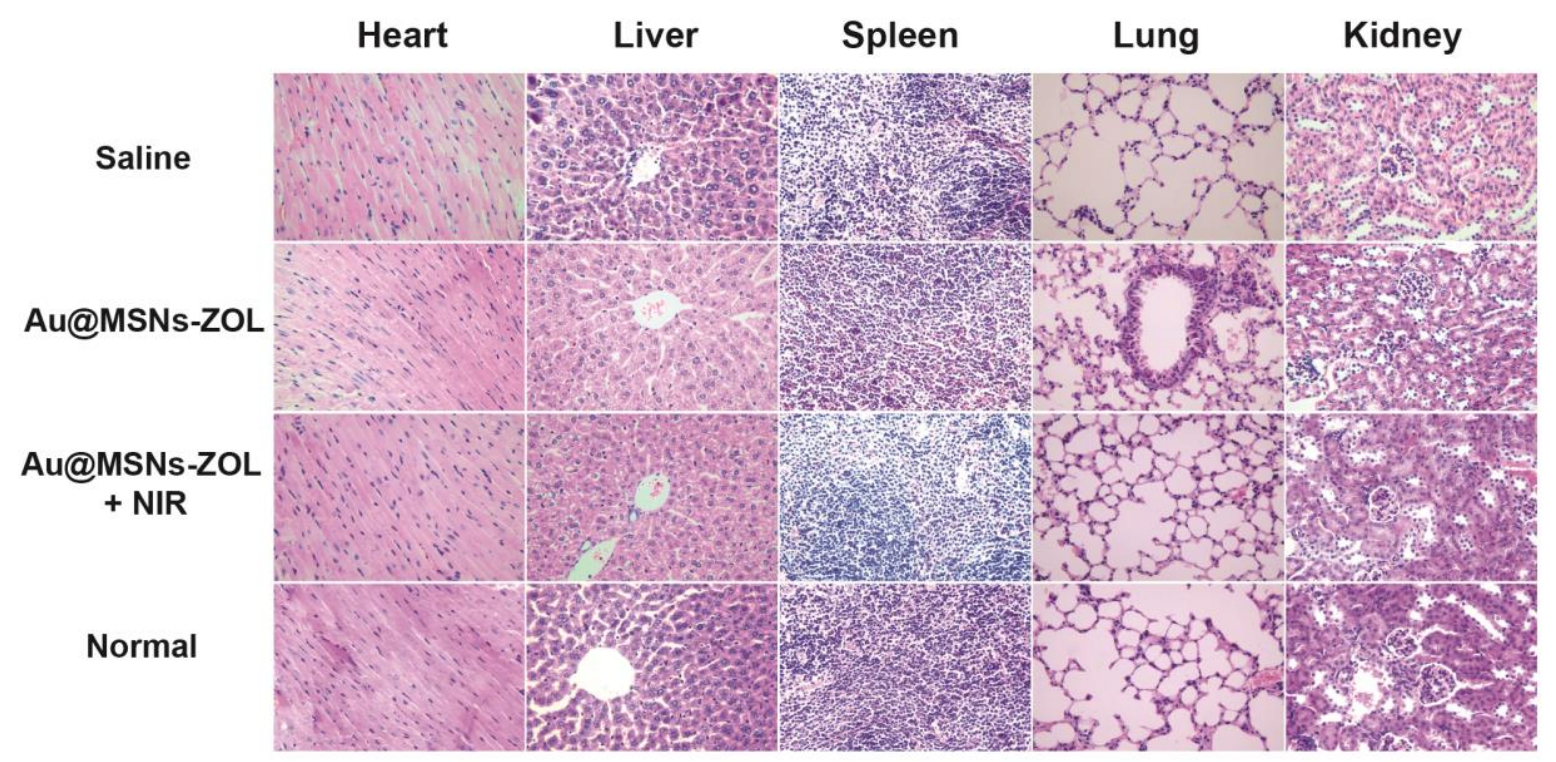

Fig. S7 HE staining of organs from mice after treated with saline, Au@MSNs-ZOL, and combination of $\mathrm{Au} @ \mathrm{MSNs}-\mathrm{ZOL}$ and NIR for 35 days.

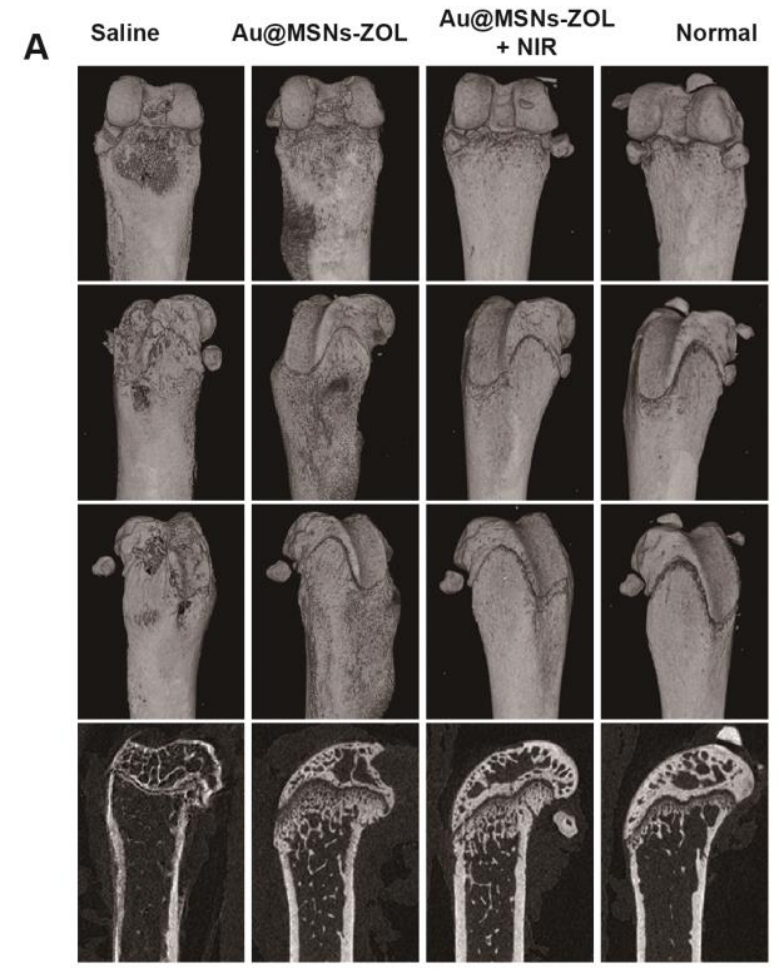

B
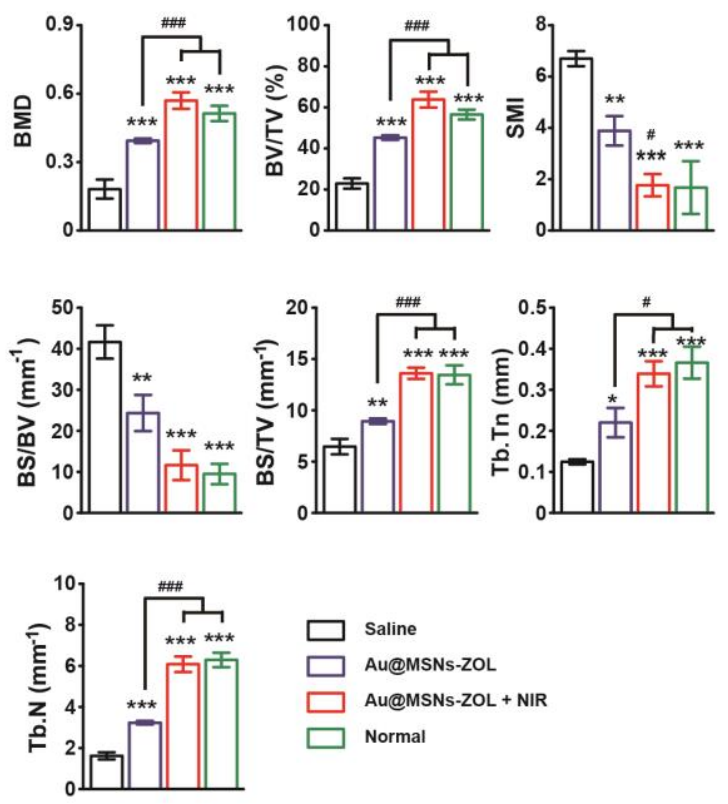

Fig. S8 CT images (A) of femur from different angles and bone parameters (B) from (A) at the end of the treatment ( 35 days). 


\section{References}

(1) Yang, X.; Liu, X.; Liu, Z.; Pu, F.; Ren, J.; Qu, X. Near-Infrared Light-Triggered, Targeted Drug Delivery to Cancer Cells by Aptamer Gated Nanovehicles. Adv Mater 2012, 24, $2890-2895$.

(2) Xue, X.; Zhao,Y.; Zhang, X.; Zhang, C.; Kumar, A.; Zhang, X.; Zou G.; Wang, P. C.; Zhang, J.; Liang, X-J. Phenylboronic Acid Functionalized Magnetic Nanoparticles for One-Step Saccharides Enrichment and Mass Spectrometry Analysis. Biophys Rep 2015, 1, $61-70$.

(3) Pan, L.; Liu, J.; He, Q.; Shi, J. MSN-Mediated Sequential Vascular-to-Cell Nuclear-Targeted Drug Delivery for Efficient Tumor Regression. Adv Mater 2014, 26, $6742-6748$.

(4) Sun, W.; Han, Y.; Li, Z.; Ge, K.; Zhang, J. Bone-Targeted Mesoporous Silica Nanocarrier Anchored by Zoledronate for Cancer Bone Metastasis. Langmuir 2016, 32, 9237-9244. 